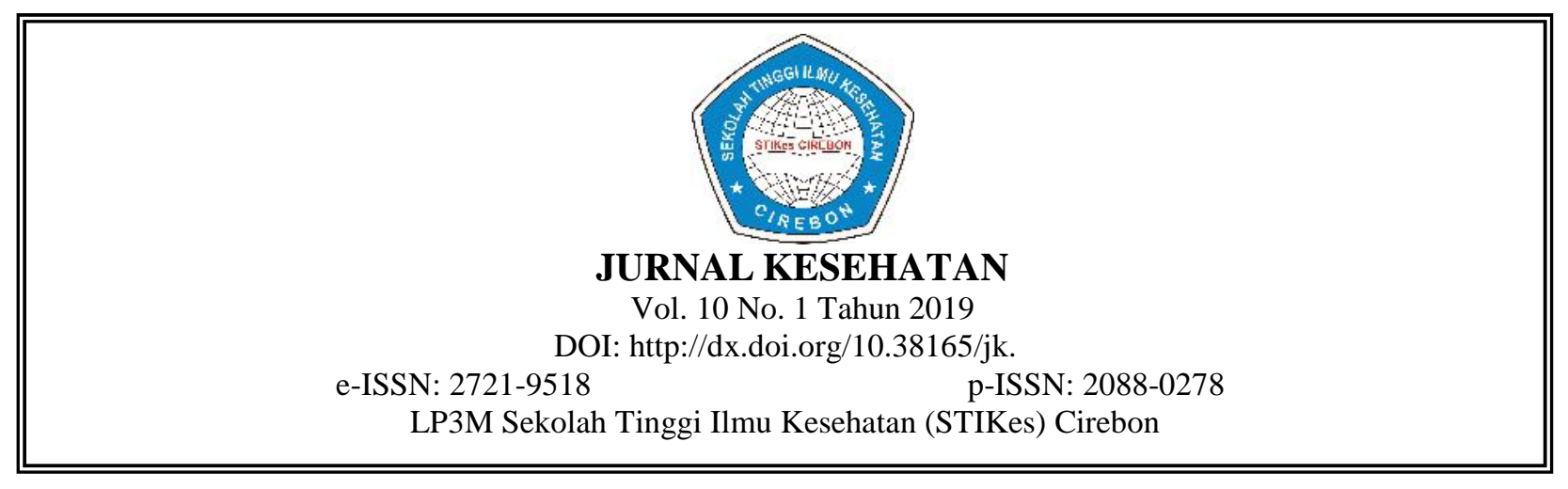

\title{
PENGARUH MASSAGE EFFLEURAGE TERHADAP PERUBAHAN TINGKAT NYERI PADA PASIEN KALA 1 FASE AKTIF PERSALINAN
}

\author{
Sri Lestari* \\ Program Studi Ilmu Keperawatan Sekolah Tinggi Ilmu Kesehatan Cirebon \\ Sri15121964@gmail.com \\ Nita Apriyani** \\ Program Studi Ilmu Keperawatan Sekolah Tinggi Ilmu Kesehatan Cirebon
}

\begin{abstract}
Abstrak
Proses persalinan dimulai pada saat terjadi kontraksi uterus yang teratur dan progresif serta akan diakhiri dengan keluarnya janin. Massage merupakan salah satu metode non farmakologi yang dapat menimbulkan efek relaksasi. Tujuan penelitian ini adalah untuk mengetahui pengaruh massage effleurage terhadap perubahan tingkat nyeri kala 1 fase aktif persalinan di Wilayah Kerja Puskesmas Plered Kabupaten Cirebon Tahun 2018. Jenis penelitian quasi eksperimental dengan menggunakan rancangan penelitian pre and post test without control. Populasi dalam penelitian ini adalah semua pasien yang akan melahirkan pada bulan Maret yang berjumlah 42 orang dan metode pengambilan sampel menggunakan teknik purposive sampling sebanyak 38 orang. Pengumpulan data dilakukan dengan teknik wawancara. Instrumen penelitian yang digunakan dalam penelitian ini adalah Skala nyeri numerik atau Numerical Rating Scale (NRS). Metode analisis data menggunakan teknik analisis statistik non parametrik dengan uji Wilcoxon. Hasil penelitian ini menunjukan bahwa tingkat nyeri persalinan sebelum diberikan intervensi adalah nyeri berat (ratarata 7,37) dan setelah diberikan intervensi adalah nyeri tingkat sedang (rata-rata 4,95). Penurunan tingkat nyeri setelah diberikan intervensi adalah 2,42. Hasil uji statistik diperoleh nilai p 0,000 lebih kecil dari nilai $\alpha 0,05$ dengan demikian massage effleurage efektif menurunkan nyeri kala 1 fase aktif persalinan.
\end{abstract}

Kata kunci: Nyeri, kala 1, massage effleurage

\begin{abstract}
The labor started as a contraction of the uterus that is orderly and progressive and will and with the release of the fetus. Massage is one of the methods for the pharmacology that could lead to the effect of relaxation. The purpose of this research is to know the effect of massage effleurage to change on the level on labor pain of stage I of active phase at plered public health centre, Cirebon 2018. This type of research is quasi experimental with pre and post test without control design. The population in this research is all the patients who want birthing in March, which has 42 people, and the method of sampling is purposive sampling as many as 38 people. Data collection is done by interview techniques. The research instrument used in this study was the Numerical Rating Scale (NRS).

The data of the research were analyzed by using the statistical non-parametric Wilcoxon test. The results showed that the level of pain of labor before being given intervention is pain severe (the average 7,37) and after giver intervention the pain is moderate (the average 4,95). Thus, the level of labor pain declines as much as 2,42 following the treatment. The result of the analysis shows that the value of $p$ is 0,000, which is smaller than the value of $\alpha=0,05$, meaning that the effleurage massage is are effective to reduce the labor pain of stage I of active phase.
\end{abstract}

Keywords: Pain, active phase, effleurage massage 


\section{PENDAHULUAN}

Kematian saat melahirkan menjadi penyebab utama mortalitas wanita pada masa puncak produktivitasnya. WHO memperkirakan di seluruh dunia setiap setiap tahunnya lebih dari 585.000 jiwa meninggal saat hamil atau bersalin. ${ }^{1}$

Kematian dan kesakitan ibu hamil, bersalin dan nifas, masih merupakan masalah besar di negara berkembang termasuk di Indonesia. Menurut data WHO, sebanyak 99\% kematian ibu akibat masalah persalinan atau kelahiran terjadi di Negara-negara berkembang. ${ }^{1}$

Berdasarkan isi tujuan MDGs (Millenium Development Goals) yang kelima yaitu meningkatkan kesehatan ibu, dengan target menurunkan tingkat kematian ibu sebesar seperempatnya antara 1990-2015, pada tahun 2015 Indonesia ditargetkan untuk angka kematian ibu adalah 102 kematian per 100.000 kelahiran hidup. Sementara itu berdasarkan Survei Demografi dan Kesehatan Indonesia (SDKI) tahun 2012 angka kematian ibu sebesar 359 per 100.000 kelahiran hidup. Angka ini masih cukup jauh dari target yang harus dicapai pada tahun $2015 .^{2}$

Menurut Dinas Kesehatan Provinsi Jawa Barat, jumlah kasus kematian ibu di Provinsi Jawa Barat tahun 2014 berdasarkan laporan dari kabupaten/kota sebanyak 747 kematian ibu. kematian maternal di kota Cirebon sebanyak 3 kematian. Kematian ibu disebabkan oleh faktor penyebab langsung, yaitu satu orang karena eklamsia dan dua orang mengalami perdarahan karena atonia uteri. $^{3}$

Persalinan merupakan suatu peristiwa yang menegangkan bagi kebanyakan wanita. Seorang wanita yang sedang mengalami persalinan cenderung merasa takut dan cemas, terutama pada ibu primigravida. Wall dan Malzack meyakini bahwa nyeri harus diringankan dengan efektif, karena bila nyeri disertai dengan reaksi stress memiliki efek yang berbahaya bagi ibu dan kemungkinan juga pada janin. ${ }^{4}$

Sebagian besar (90\%) persalinan pasti disertai dengan nyeri. Nyeri pada saat persalinan merupakan suatu kondisi fisiologis yang secara umum dialami oleh hampir semua ibu bersalin. Nyeri persalinan merupakan suatu pengalaman subjektif tentang sensasi fisik terkait dengan kontraksi uterus, dilatasi dan penipisan serviks, serta penurunan janin selama persalinan. ${ }^{5}$

Nyeri berasal dari kontraksi uterus dan dilatasi serviks. Dengan semakin bertambahnya volume dan frekuensi kontraksi uterus, maka nyeri dirasakan juga akan semakin kuat. Secara fisiologis nyeri persalinan mulai timbul pada kala 1 fase laten dan fase aktif, pada fase laten terjadi pembukaan serviks sampai $3 \mathrm{~cm}$ yang dapat berlangsung selama 8 jam. Pada fase aktif nyeri akan mencapai puncaknya yaitu pada pembukaan lengkap sampai $10 \mathrm{~cm}$, dimana pada primigravida kala 1 persalinan dapat berlangsung \pm 20 jam dan pada multigravida kala 1 persalinan bisa berlangsung selama \pm 14 jam. Intensitas nyeri selama persalinan mempengaruhi kondisi psikologis ibu, proses persalinan dan kesejahteraan janin. ${ }^{6}$

Rasa nyeri pada persalinan muncul akibat respons psikis dan refleks fisik. Nyeri persalinan dapat menyebabkan perubahan tekanan darah, denyut nadi, pernafasan, dan warna kulit serta keringat berlebihan. Nyeri yang terjadi juga dapat mempengaruhi kondisi psikologis ibu berupa kelelahan, rasa takut, khawatir dan menimbulkan stress. Stress dapat menyebabkan melemahnya kontraksi rahim dan berakibat pada persalinan yang lama. ${ }^{7}$

Jika hal tersebut tidak diatasi dengan cepat maka akan mengakibatkan kematian pada ibu dan bayi karena nyeri menyebabkan pernafasan dan denyut jantung ibu akan meningkat yang menyebabkan aliran darah dan oksigen ke plasenta terganggu. Penanganan dan pengawasan nyeri persalinan terutama pada kala 1 fase aktif sangat penting, karena sebagai titik penentu apakah dapat menjalani persalinan normal atau diakhiri dengan suatu tindakan. ${ }^{8}$

Penanganan nyeri dalam persalinan merupakan hal utama yang harus diperhatikan oleh pemberi asuhan kesehatan saat memberikan pertolongan persalinan. Bukan jumlah nyeri yang dialami wanita yang perlu dipertimbangkan, akan tetapi harapan tentang cara mengatasi nyeri tersebut dapat dipenuhi. Banyak cara yang dapat digunakan dalam menangani rasa nyeri saat persalinan, antara lain dengan tindakan farmakologis dan tindakan non farmakologis. ${ }^{8}$ 
Penanganan nyeri dengan tindakan farmakologis dilakukan dengan pemberian obat-obatan, diantaranya penggunaan analgesik, suntikan epidural, dan lain-lain.Walaupun obat-obatan lebih efektif dalam mengurangi nyeri tetapi mempunyai efek samping yang kurang baik untuk ibu maupun janin. Misalnya pada analgesik dapat menimbulkan perasaan mual dan pusing pada ibu serta ibu menjadi tidak dapat mengandalkan otot perutnya untuk mendorong ketika terjadi kontraksi rahim sehingga persalinan berlangsung lebih lama. ${ }^{5}$

Tindakan non farmakologis dalam manajemen nyeri merupakan trend baru yang dapat dikembangkan dan merupakan metode alternatif yang dapat digunakan pada ibu untuk mengurangi nyeri persalinan. Dimana tercantum juga dalam Undang-Undang Keperawatan No.38 Tahun 2014 pasal 30 ayat (2) bahwa dalam menjalankan tugasnya sebagai pemberi asuhan keperawatan, perawat berwenang melakukan penatalaksanaan keperawatan komplementer dan alternatif. Tindakan non farmakologis merupakan tindakan keperawatan komplementer dan alternatif. ${ }^{9}$

Metode non farmakologis dapat memberikan efek relaksasi kepada pasien dan dapat membantu meringankan ketegangan otot dan emosi serta mengurangi nyeri persalinan. Metode non farmakologis juga dapat meningkatkan kepuasan selama persalinan, karena ibu dapat mengontrol perasaannya dan kekuatannya. Beberapa teknik non farmakologis yang dapat digunakan antara lain relaksasi, teknik pernapasan, pergerakan dan perubahan posisi, massage, hydrotherapy, terapi panas atau dingin, musik, guided imagery, akupresur dan aromaterapi. Teknik tersebut dapat meningkatkan kenyamanan ibu saat bersalin dan mempunyai pengaruh pada koping yang efektif terhadap pengalaman persalinan. ${ }^{8}$

Massage atau pijat merupakan terapi nyeri yang paling primitif yang menggunakan refleks lembut manusia untuk menahan, menggosok atau meremas bagian tubuh yang nyeri. Massage dilakukan dengan tindakan penekanan oleh tangan pada jaringan lunak, biasanya otot, tendon atau ligamentum, tanpa menyebabkan gerakan atau perubahan posisi sendi untuk meredakan nyeri, menghasilkan relaksasi, dan atau memperbaiki sirkulasi. ${ }^{5}$

Terdapat enam gerakan dasar dalam massage. Gerakan dasar tersebut adalah: effleurage (gerakan tangan mengurut), pettrissage (gerakan tangan mencubit), tapotement (gerakan tangan melakukan perkusi), hacking (gerakan tangan mencincang), kneading (gerakan tangan meremas), dan cupping (gerakan tangan membentuk seperti mangkuk). Setiap gerakan ditandai dengan perbedaan tekanan, arah, kecepatan, posisi tangan dan gerakan untuk mencapai pengaruh yang berbeda pada jaringan dibawahnya. ${ }^{5}$

Tindakan utama massage dianggap 'menutup gerbang' untuk menghambat perjalanan rangsang nyeri pada pusat yang lebih tinggi pada sistem saraf pusat. Selanjutnya rangsangan tektil dan perasaan positif, yang berkembang ketika dilakukan bentuk sentuhan yang penuh perhatian dan empatik, bertindak memperkuat efek massage untuk mengendalikan nyeri. ${ }^{5}$

Ibu yang dipijat dua puluh menit setiap jam selama persalinan akan lebih terbebas dari rasa sakit karena pijatan merangsang tubuh untuk melepaskan senyawa endorphin yang merupakan pereda rasa sakit. Endorphin juga dapat menciptakan rasa rileks dan nyaman dalam persalinan. Banyak wanita merasa bahwa pijatan sangat efektif dalam menghilangkan rasa sakit pada saat melahirkan yang secara umum akan membantu menyeimbangkan energi, merangsang dan mengatur tubuh memperbaiki sirkulasi darah, kelenjar getah bening sehingga oksigen, zat makanan dan sisa makanan dibawa secara efektif dari jaringan tubuh ibu ke plasenta dengan mengendurkan ketegangan yang membantu menurunkan emosi. ${ }^{4}$

Umumnya, ada dua teknik pemijatan yang dilakukan dalam persalinan yaitu effleurage dan counterpressur. Effleurage adalah teknik pemijatan berupa usapan lembut, lambat dan panjang atau tidak putus-putus.Teknik ini menimbulkan relaksasi. Dalam persalinan, effleurage dilakukan dengan menggunakan ujung jari yang lembut dan ringan. Lakukan usapan dengan ringan dan tanpa tekanan kuat, tetapi usahakan ujung jari tidak lepas dari permukaan kulit. Teknik ini lebih dipilih karena hanya berupa usapan ringan dan tanpa ada penekanan sehingga tidak berbahaya bagi ibu dan janin. 
Effleurage atau pijatan pada abdomen yang teratur dengan latihan pernapasan selama kontraksi digunakan untuk mengalihkan wanita dari nyeri selama persalinan. Begitu pula adanya massage yang mempunyai efek distraksi juga dapat meningkatkan pembentukan endorphin dalam sistem kontrol dasenden. Massage dapat membuat pasien lebih nyaman karena massage membuat relaksasi otot. ${ }^{4}$

Pada penelitian sebelumnya yang dilakukan oleh Marni Wahyuningsih tahun 2014 yang berjudul Efektifitas aroma terapi lavender (lavandula angustifolia) dan massage effleurage terhadap tingkat nyeri persalinan kala 1 fase aktif pada primigravida di BPS Utami dan RSUD Karanganyar diperoleh hasil uji statistik nilai $\mathrm{p} 0,00$ lebih kecil dari nilai $\alpha$ 0,05 dengan penurunan tingkat nyeri setelah diberikan intervensi adalah 2,938, yang berarti aromaterapi lavender dan massage effleurage efektif menurunkan tingkat nyeri persalinan kala 1 fase aktif pada primigravida. ${ }^{8}$

Berdasarkan studi pendahuluan yang dilakukan di wilayah kerja Puskesmas Plered Kabupaten Cirebon pada tanggal 11 November 2018 diperoleh data tiga bulan terakhir yaitu bulan SeptemberNovember 2018 mencapai 117 persalinan. Dimana pada Desa Panembahan terdapat 16 persalinan, di Desa Trusmi Wetan terdapat 11 persalinan, di Desa Trusmi Kulon terdapat 14 persalinan, di Desa Wotgali terdapat 22 persalinan, di Desa Kaliwulu terdapat 27 Persalinan, dan di Desa Tegal Sari terdapat 27 persalinan. ${ }^{10}$

Berdasarkan informasi hasil wawancara dengan bidan yang bertugas di Puskesmas Plered Kabupaten Cirebon dan bidan desa, pada saat terjadi kontraksi pada kala 1 persalinan dan terjadi nyeri hebat, bidan dan keluarga pasien hanya menggosok punggung pasien dengan maksud untuk menenangkan pasien agar nyeri tidak bertambah berat, tetapi hasilnya tidak signifikan, terdapat pasien yang nyerinya berkurang dan ada juga yang tingkat nyerinya tetap. Hal ini juga tergantung pada tingkat toleransi individu terhadap nyeri.

Berdasarkan latar belakang di atas maka peneliti berkeinginan melakukan penelitian mengenai penanganan tingkat nyeri persalinan dengan teknik yang lain yaitu massage effleurage pada pasien kala 1 fase aktif persalinan di Wilayah Kerja Puskesmas Plered Kabupaten Cirebon. Tujuan Penelitian ini untuk mengetahui pengaruh massage effleurage terhadap perubahan tingkat nyeri pada pasien kala 1 fase aktif persalinan di Wilayah Kerja Puskesmas Plered Kota Cirebon.

\section{METODE PENELITIAN}

Desain penelitian ini adalah quasi experimental dengan rancangan pre and post test without control design. Populasi dalam penelitian ini adalah semua pasien yang akan melahirkan secara normal di Wilayah Kerja Puskesmas Plered Kabupaten Cirebon yaitu sebanyak 42 orang. Sampel dalam penelitian ini menggunakan purposive sampling. Sampel yang memenuhi kriteria dalam penelitian ini sebanyak 38 orang. Responden berada di Wilayah Kerja Puskesmas Plered Kabupaten Cirebon. Pengumpulan data dilakukan dengan teknik wawancara. Instrumen penelitian yang digunakan dalam penelitian ini adalah Skala nyeri numerik atau Numerical Rating Scale (NRS). Data dianalisis dengan analisis dengan analisis univariat dan bivariat, menggunakan uji Wilcoxon.

\section{HASIL PENELITIAN}

Tabel 1. Distribusi Frekuensi Tingkat Nyeri Pada Pasien Kala 1 Fase Aktif Persalinan Sebelum Dilakukan Massage Effleurage

\begin{tabular}{ccc}
\hline Tingkat Nyeri & Frekuensi & Persentase $(\%)$ \\
\hline Tidak Nyeri & 0 & 0 \\
Nyeri Ringan & 0 & 0 \\
Nyeri Sedang & 8 & 21,1 \\
Nyeri Berat & 30 & 78,9 \\
\hline Total & 38 & 100 \\
\hline
\end{tabular}


Berdasarkan tabel 1, terlihat bahwa tingkat nyeri pada pasien kala 1 fase aktif persalinan sebelum dilakukan massage effleurage sebagian besar dengan intensitas nyeri berat yaitu 30 orang $(78,9 \%)$.

Tabel 2. Distribusi Frekuensi Tingkat Nyeri Pada Pasien Kala 1 Fase Aktif Persalinan Sesudah Dilakukan Massage Effleurage

\begin{tabular}{ccc}
\hline Tingkat Nyeri & Frekuensi & Persentase $(\%)$ \\
\hline Tidak Nyeri & 0 & 0 \\
Nyeri Ringan & 12 & 31,6 \\
Nyeri Sedang & 22 & 57,9 \\
Nyeri Berat & 4 & 10,5 \\
\hline Total & 38 & 100 \\
\hline
\end{tabular}

Berdasarkan tabel 2, terlihat bahwa tingkat nyeri pada pasien kala 1 fase aktif persalinan sesudah dilakukan massage effleurage sebagian besar dengan intensitas nyeri sedang yaitu 22 orang $(57,9 \%)$.

Tabel 3. Pengaruh dilakukannya massage effleurage terhadap perubahan tingkat nyeri pada pasien kala 1 fase aktif persalinan

\begin{tabular}{lccccc}
\hline & $\mathrm{N}$ & Mean & Minimum & Maksimum & P value \\
\cline { 1 - 4 } Tingkat Nyeri Sebelum & 38 & 7,37 & 5 & 9 & 0,000 \\
Tingkat Nyeri Sesudah & 38 & 4,95 & 3 & 8 & \\
\hline
\end{tabular}

Berdasarkan tabel 3 setelah dilakukan uji Wilcoxon berdasarkan dari hasil tabel statistik didapatkan nilai $\mathrm{p}$ sebesar 0,000. Dengan demikian nilai $\mathrm{p}$ lebih kecil dari $\alpha(5 \%)$ atau 0,05 sehingga $\mathrm{HO}$ ditolak dan Ha diterima, maka massage effleurage berpengaruh dalam menurunkan tingat nyeri pada pasien kala 1 fase aktif persalinan.

\section{PEMBAHASAN}

Ada pengaruh massage effleurage terhadap nyeri pada pasien fase aktif kala 1 dalam proses persalinan, di Puskesmas Plered Kabupaten Cirebon tahun 2018. Sesuai dengan teori Melzack, yang menyatakan bahwa usia ibu mempengaruhi derajat nyeri persalinan, semakin muda usia ibu $(<20$ tahun) maka akan semakin nyeri bila dibandingkan dengan usia ibu yang lebih tua. Usia mempengaruhi keberhasilan seorang ibu dalam melaksanakan peran sebagai ibu, usia juga menentukan kesiapan dalam memutuskan dan bertindak yang dalam hal ini kesiapan seorang ibu bersalin dalam menghadapi persalinannya.

Tingkat pendidikan berpengaruh dalam memberikan respon terhadap segala sesuatu yang datang dari luar, dimana seseorang dengan pendidikan tinggi akan memberikan respon lebih rasional daripada yang berpendidikan menengah atau rendah. Sebagian besar responden dalam penelitian ini mempunyai tingkat pendidikan akhir SMA yaitu sebanyak 29 orang (76,2\%), sedangkan yang mempunyai tingkat pendidikan SD sebanyak 2 orang $(5,3 \%)$, SMP sebanyak 5 orang (13,2\%), dan Perguruan Tinggi sebanyak 2 orang (5,3\%). Tingkat pendidikan mempengaruhi persepsi seseorang dalam merasakan nyeri pada proses modulasi. Proses ini menyebabkan persepsi nyeri menjadi subjektif dan ditentukan oleh makna atau arti suatu input nyeri. Orang yang memiliki pendidikan tinggi diasumsikan lebih mudah menyerap informasi. Pengetahuan tentang pengelolaan nyeri dapat diperoleh dari pengalaman klien sendiri atau dari sumber lain.

Dengan demikian diharapkan kepada semua ibu yang akan menghadapi persalinan untuk secara rutin dalam melakukan kunjungan antenatal care. Hal ini dimaksudkan agar tiap ibu dapat menerima informasi yang diberikan oleh petugas kesehatan termasuk persiapan bagi ibu dalam menghadapi persalinannya kelak. Sehingga tiap ibu yang bersalin dapat mempunyai gambaran tentang apa yang akan dialami termasuk nyeri pada persalinan. 
Sebuah penelitian menyebutkan, ibu yang dilakukan massage 20 menit setiap jam selama tahap persalinan akan lebih bebas dari rasa sakit. Hal ini dikarenakan massage merangsang tubuh melepaskan senyawa endorphin yang dapat menghilangkan sakit secara ilmiah sehingga lebih nyaman. Pada saat persalinan dianjurkan agar massage dilakukan terus menerus, karena rasa nyeri cenderung akan meningkat jika massage dihentikan. Hal tersebut terjadi karena sistem saraf menjadi terbiasa terhadap stimulus berhenti merespon nyeri tersebut. ${ }^{6}$

Pijatan dapat menenangkan dan merilekskan ketegangan yang muncul saat hamil dan melahirkan. Usapan pelan pada perut akan terasa nyaman saat kontraksi. ${ }^{11}$

Hal ini menunjukan bahwa massage effleurage merupakan suatu cara untuk menurunkan intensitas nyeri pada pasien kala 1 fase aktif persalinan. Massage effleurage adalah teknik pemijatan berupa usapan lembut, lambat dan panjang atau tidak putus-putus. ${ }^{4}$

Pijat (massage) membantu ibu merasa lebih segar, rileks, dan nyaman selama persalinan. Sebuah penelitian menyebutkan ibu yang dipijat selama 20 menit setiap jam selama tahap persalinan akan lebih bebas dari rasa sakit. Hal itu terjadi karena pijat merangsang tubuh melepaskan senyawa endorphin yang merupakan pereda sakit alami. Endorphin juga dapat menciptakan perasaan nyaman dan enak. Dalam persalinan, pijat juga membuat ibu merasa lebih dekat dengan orang yang merawatnya. ${ }^{4}$

Dalam penelitian ini didapatkan hasil bahwa terjadi penurunan tingkat nyeri setelah dilakukan massage effleurage. Pemberian massage effleurage pada abdomen menstimulasi serabut taktil dikulit sehingga sinyal nyeri dapat dihambat. Stimulasi kulit dengan effleurage ini menghasilkan pesan yang dikirim lewat serabut beta-A, serabut yang menghantarkan nyeri cepat, yang mengakibatkan gerbang tertutup sehingga korteks serebri tidak menerima sinyal nyeri dan intensitas nyeri berubah atau berkurang.

Hasil penelitian ini sesuai dengan Gate Control Teori yaitu bahwa serabut nyeri membawa stimulasi nyeri ke otak lebih kecil dan perjalanan sensasinya lebih lambat dari pada serabut yang luas dan sensasinya berjalan lebih cepat. Ketika sentuhan dan nyeri dirangsang bersama sensasi sentuhan berjalan ke otak dan menutup pintu gerbang dalam otak dan terjadi pembatasan intensitas nyeri di otak. Massage merupakan distraksi yang dapat meningkatkan pembentukan endorphin dalam sistem kontrol desenden sehingga dapat membuat pasien lebih nyaman karena relaksasi otot. ${ }^{5}$

Berdasarkan uraian diatas peneliti berpendapat bahwa nyeri ini bisa dipengaruhi oleh arti nyeri yang dirasakan seseorang, persepsi nyeri, dan reaksi nyeri yang merupakan respon seseorang terhadap nyeri seperti ketakutan, kecemasan, gelisah, menangis, dan menjerit dan dapat juga dipengaruhi oleh usia dan pendidikan. Nyeri ini dapat diatasi dengan menggunakan massage effleurage. Pasien yang mendapatkan massage ini akan merasa tenang, nyaman, rileks, puas dan akan lebih dekat dengan petugas kesehatan yang melayani.

\section{SIMPULAN}

Berdasarkan pada analisis hasil dan pembahasan tersebut di atas, maka dapat diambil kesimpulan sebagai berikut:

1. Tingkat nyeri pada pasien kala 1 fase aktif persalinan, sebelum dilakukan massage berada pada kategori nyeri berat yaitu 30 responden $(78,9 \%)$.

2. Tingkat nyeri pada pasien kala 1 fase aktif persalinan setelah dilakukan massage mengalami nyeri sedang yaitu 22 responden $(57,9 \%)$.

3. Terdapat perbedaan rata-rata tingkat nyeri pada pasien kala 1 fase aktif persalinan sebelum massage effleurage dan sesudah massage effleurage, maka massage effleurage efektif menurunkan tingat nyeri pada pasien kala 1 fase aktif persalinan.

\section{SARAN}

Diharapkan ibu-ibu bersalin yang berada pada kala 1, fase aktif persalinan bisa melakukannya secara mandiri massage effleurage dengan baik. Puskesmas Plered sebaiknya meningkatkan penyuluhan tentang massage effleurage pada ibu-ibu dalam proses persalinan atau 
pada trimester akhir persalinan. Melakukan massage effleurage pada ibu-ibu pada fase aktif kala 1 persalinan.

\section{DAFTAR PUSTAKA}

1. Angka kematian ibu di Indonesia. [Diakses tanggal 14 November 2018]. Tersedia dari: http://www.depkes.go.id/download.php?file=download/pusdatin/infodatin-ibu.pdf

2. Dita Anugrah.Angka Kematian Ibu di Indonesia Masih Jauh dari Target MDGs 2015. [Diakses tanggal 27 November 2015]. Tersedia dari: http://www.kompasiana.com/ditaanugrah/angka_kematian_ibu_di_indonesia_masih_jauh_dari _target_2015.html

3. Profil Kesehatan Provinsi Jawa Barat. [Diakses tanggal 14 November2018]. Tersedia dari: http://www.depkes.go.id/resources/download/profil/PROFIL_KES_PROVINSI_2012/12_profil _Kes.Prov.Jawa Barat_2012.pdf

4. Danuatmaja, B., Meiliasari, M. Persalinan normal tanpa rasa sakit. Jakarta: Puspa Swara; 2011.

5. Mander, Rosemary. Nyeri persalinan. Jakarta: EGC; 2012.

6. Potter, Patricia A., Perry, Anne G. Buku ajar fundamental keperawatan. Jakarta: EGC; 2010.

7. Nastiti, R.K.R., Rejeki, S., Nurullita, U. Perbedaan efektivitas teknik back-effleurage dan teknik counter pressure terhadap tingkat nyeri pinggang kala 1 fase aktif persalinan. Jurnal. Universitas Muhamadiyah Semarang; 2012.

8. Wahyuningsih, M. Efektivitas aroma terapi lavender dan massage effleurage terhadap tingkat nyeri persalinan kala 1 fase aktif para primigravida. Skripsi. STIKes Kusuma Husada Surakarta; 2014.

9. Anonim. Data Laporan PWS kesehatan ibu Puskesmas Plered Kabupaten Cirebon Tahun 2015. Cirebon: Puskesmas Plered:2016

10. Brunner \& Suddarth. Buku ajar keperawatan medikal bedah. Edisi 8. Jakarta: EGC; 2014.

11. Bobak, Lowdermilk \& Jensen. Buku ajar keperawatan maternitas. Jakarta: EGC; 2011.

12. Monsdragon. Pregnancy information (effleurage dan massage). [Diakses tanggal 4 Desember 2018]. Tersedia dari: http://www.monsdragon.org/pregnancyeffleurage.html.

13. Notoatmodjo, Soekidjo. Metodologi penelitian kesehatan. Jakarta: Rineka Cipta; 2012. 